\title{
Cenário internacional e desempenho da economia brasileira
}

\author{
Marcio José Vargas da Cruz* \\ Marcelo Luiz Curado**
}

RESUMO - A possibilidade de recessão da economia norte-americana tende a resultar na redução do crescimento da demanda mundial e conseqüentemente na redução do crescimento das economias asiáticas, as mais dinâmicas do mundo atualmente, que têm nas exportações um vetor importante. Se isso de fato ocorrer, haverá uma tendência de queda dos preços das commodities, o que afetará diretamente a economia brasileira, que vem se beneficiando do comércio internacional através da exportação de bens básicos. Porém, o impacto negativo da recessão norte-americana tende a ser minimizado no curto prazo em função da maior representatividade econômica da Ásia, especialmente da China, e da dinâmica de sua demanda doméstica, que também tem sido representativa no caso da economia brasileira, com a expansão do consumo e do investimento no período recente.

Palavras-chave: Economia internacional. Crescimento econômico. Economia brasileira.

\section{INTRODUÇÃO}

O cenário econômico internacional tem se caracterizado por uma elevada instabilidade no mercado financeiro advinda principalmente da possibilidade de recessão da economia norte-americana, que tem dentre suas origens problemas relacionados ao financiamento voltado ao mercado mobiliário. As perdas dos bancos e a retração da atividade na construção civil, dentre outros acontecimentos como o aumento expressivo do preço do petróleo estão resultando na perspectiva de uma recessão nos Estados Unidos da América.

Diante da representatividade da economia estadunidense no PIB mundial, direta e indiretamente, de fato, a perspectiva de uma recessão é preocupante. Conforme apresentado no gráfico 1, considerando o PIB sob a Paridade do Poder de Compra, os EUA participam com aproximadamente 20\% do PIB mundial. Entretanto, o mesmo gráfico nos apresenta um fenômeno muito interessante, caracterizado pelo aumento da participação de economias emergentes, liderado pela China.

\footnotetext{
* Professor e vice-coordenador do curso de Ciências Econômicas da UFPR. Endereço Eletrônico: marciocruz@ufpr.br.

** Professor e chefe do departamento do curso de Ciências Econômicas da UFPR. Endereço Eletrônico: mcurado@ufpr.br.
} 


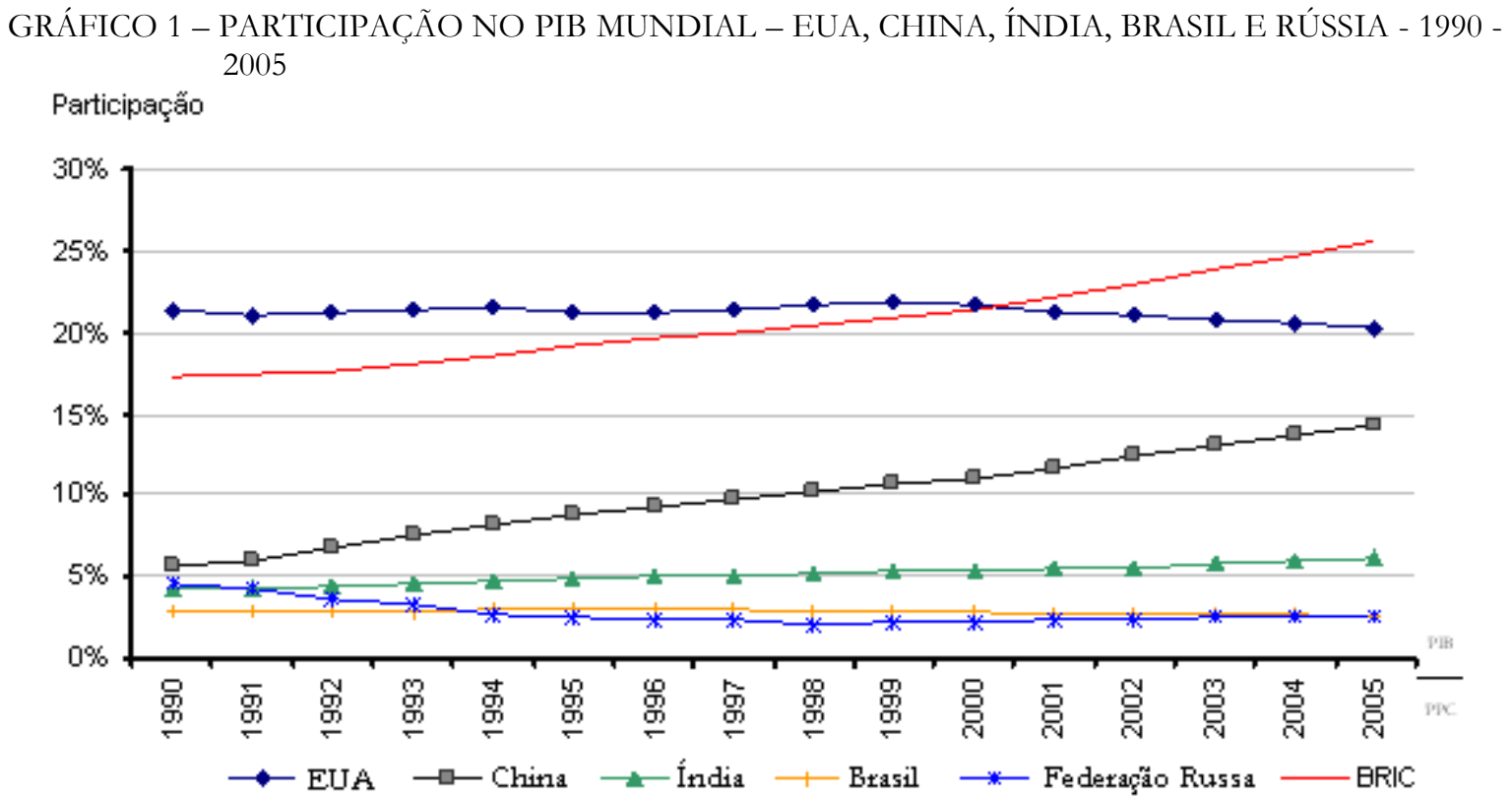

FONTE: Banco Mundial (2007).

NOTA: PIB sob a paridade do poder de compra - dólares internacionais constantes, 2000.

A China, com aproximadamente 1,3 bilhão de habitantes $(20,1 \%$ da população mundial, mais do que o dobro da população da América Latina e Caribe), de acordo com os dados disponibilizados pelo Banco Mundial teve uma participação de aproximadamente 2,8\% do PIB em 1975. Contudo, ela está prestes a alcançar três décadas de crescimento econômico médio próximo de $10 \%$ a.a, participando com $14,37 \%$ do PIB mundial em 2005. Considerado a participação conjunta das economias emergentes: Brasil, Índia, Rússia e China (BRIC), eles já têm maior participação do que os EUA no PIB mundial.

A média de crescimento destes países no período recente, entre 2000 e 2005 foi de aproximadamente 3,0\% no Brasil, 6,1\% na Índia, 9,4\% na China e 6,8\% na Rússia. Ou seja, com exceção da economia brasileira, os demais países deste grupo estão mantendo um nível de crescimento acima da média global.

Contudo, diante de um provável quadro de recessão da economia norte americana, o Fundo Monetário Internacional (FMI) tem projetado um crescimento econômico do PIB mundial para 2008, em torno de 4,1\%, que fica abaixo da média observada nos últimos três anos. Neste cenário, os EUA, o Japão e a União Européia estarão crescendo a uma taxa de aproximadamente $1,5 \%$ em 2008. Porém, cabe ressaltar que a maior incerteza reside nos efeitos da crise financeira e recessão da economia norte-americana para os anos seguintes. 
Diante deste quadro, este artigo se propõe a debater duas questões: a) Há indícios de que os países emergentes, em especial o grupo BRIC absorverão a recessão dos EUA e mesmo assim continuarão a manter uma taxa de crescimento acima da média mundial? b) Quais os efeitos esperados para a economia brasileira, com relação ao setor externo?

\section{O CENÁRIO INTERNACIONAL E A PERSPECTIVA DE RECESSÃO DA ECONOMIA NORTE-AMERICANA}

Os EUA têm apresentado uma taxa média de crescimento do PIB de aproximadamente $3,15 \%$ nos últimos 25 anos, acompanhada de recessões no início dos anos 80, 90 e 2000, motivados por origens diversas, as quais este artigo não discute. Contudo, chama a atenção a correlação observada através da análise gráfica entre o crescimento da economia norte-americana e mundial.

Considerando a série apresentada no gráfico 2, a partir de 1961, com exceção do final da década de 1970, período em que se observa um fraco crescimento da economia norteamericana descolado da tendência mundial, todos os demais períodos de recessão norteamericana, após o primeiro choque do petróleo, foram acompanhados por recessões na economia global.

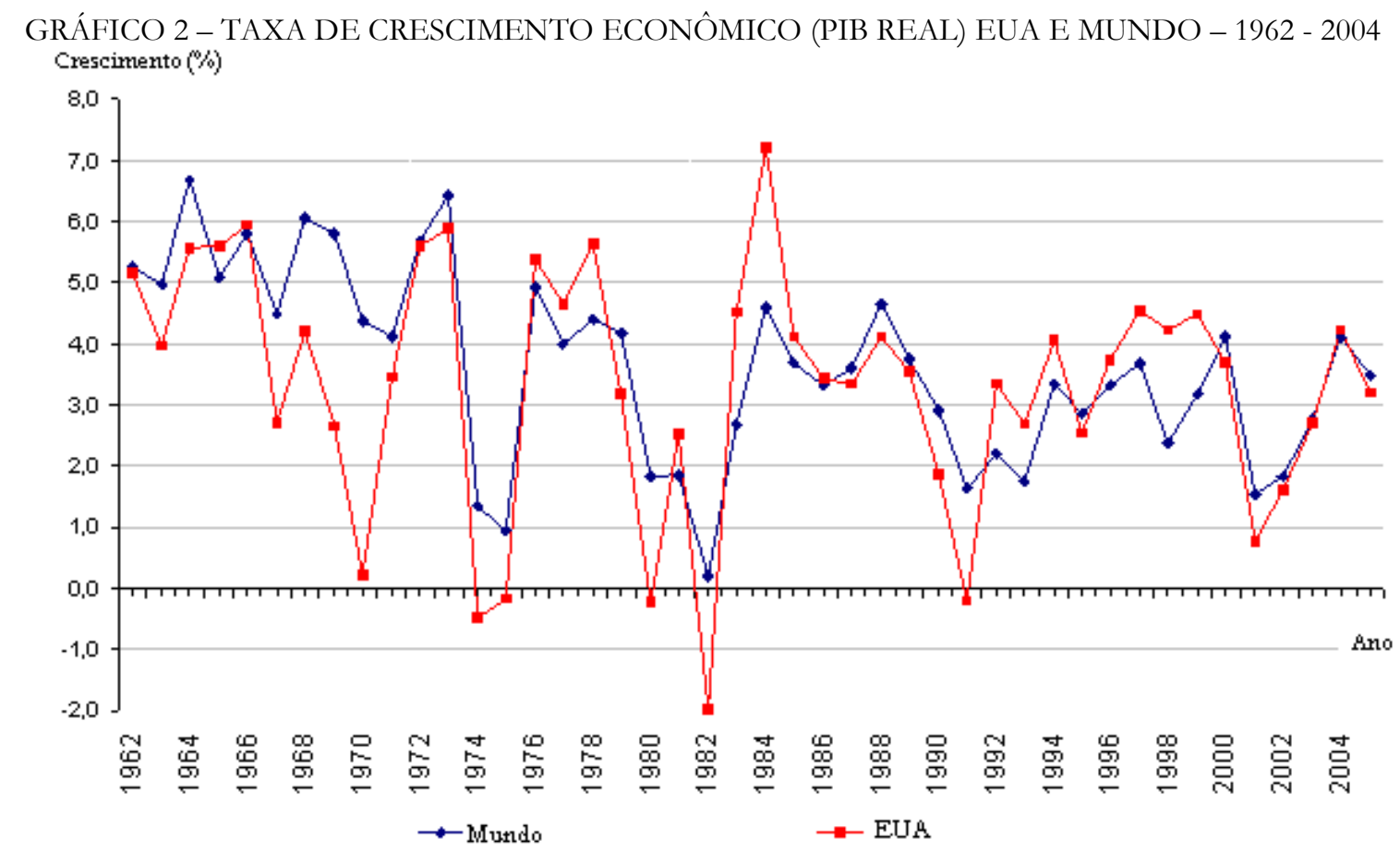

FONTE: Banco Mundial (2007).

A partir do início da década de 1970 todos os períodos nos quais a economia norteamericana cresceu menos do que $1 \%$, a economia global acompanhou a tendência de queda e 
cresceu menos do que $2 \%$. Por outro lado, todos os anos em que a economia norte-americana cresceu acima de 3\%, a economia mundial também cresceu acima deste índice.

GRÁFICO 3 - TAXA DE CRESCIMENTO ECONÔMICO (PIB REAL) CHINA E MUNDO - 1962 - 2004 21 Crescimento $\%$

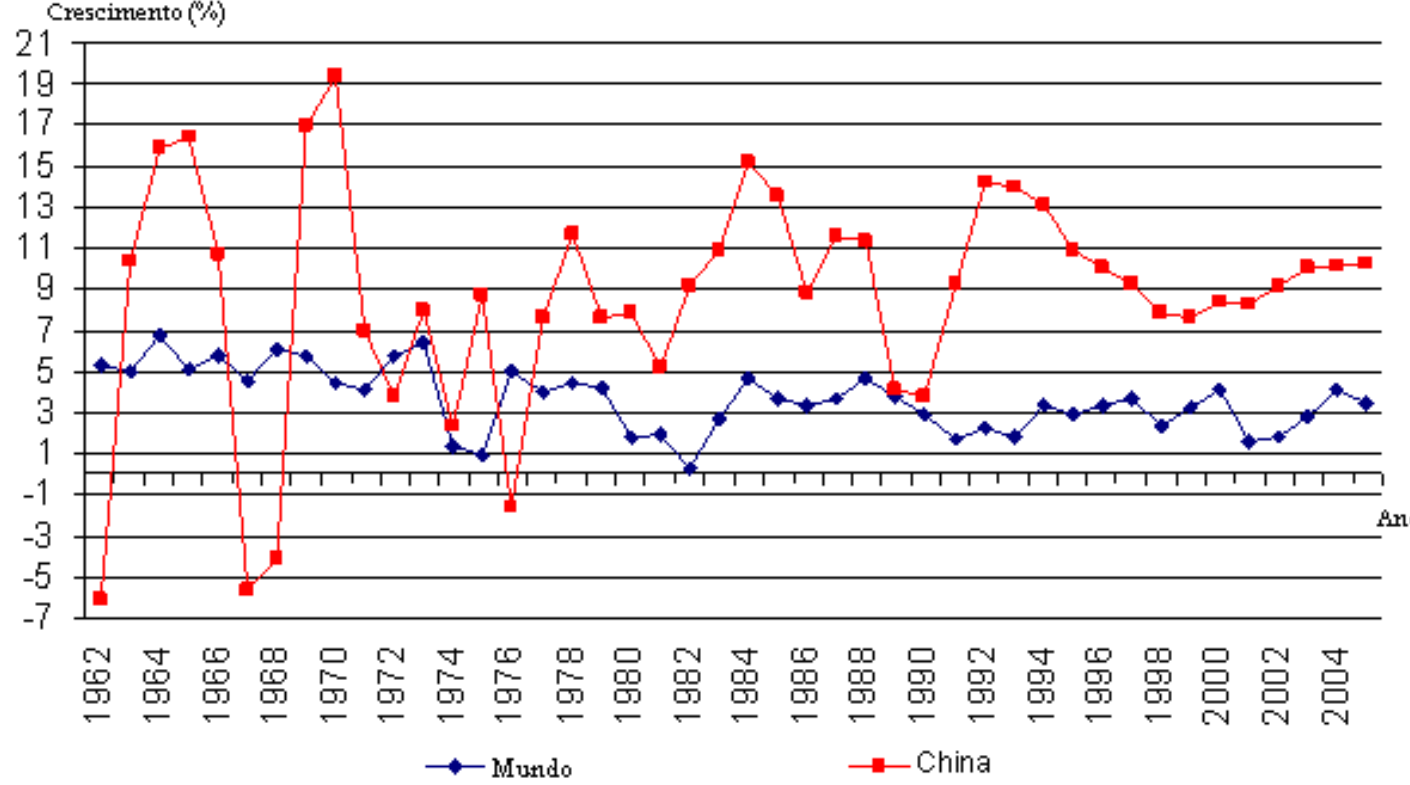

FONTE: Banco Mundial (2007).

Pelo gráfico 3 acima, se compararmos a tendência dos países que compõem o BRIC, em especial a China, que além de ser a economia mais representativa entre eles é a que tem apresentado maiores níveis de crescimento, perceberemos que a correlação para o comportamento global não fica tão evidente.

Além da maior representatividade direta na composição do PIB, é importante ressaltar que a economia norte-americana mantém um papel central geopolítico, que também se reflete no mercado financeiro e no comércio internacional. Dentre estas variáveis relevantes, será analisada a seguir a participação dos EUA no comércio internacional, uma vez que o mercado externo tem um papel importante no processo de crescimento das economias asiáticas, com destaque para a China.

A tabela 1 apresenta o desempenho e participação de alguns países no comércio internacional de bens, para alguns anos entre 1948 e 2006. Observa-se que ao longo deste período o fluxo comercial aumentou significativamente e chama a atenção a tendência de queda da participação dos EUA nas exportações mundiais, vis a vis o aumento de sua participação na importação de bens. A perda de aproximadamente 14 pontos percentuais na participação dos EUA nas exportações é acompanhada por um aumento na mesma magnitude da participação dos países asiáticos, com destaque para a China que passa em 2006 a responder por $8,2 \%$ das exportações mundiais. 
TABELA 1 - EXPORTAÇOES E IMPORTAÇOES MUNDIAIS DE BENS, POR REGIÕES E DETERMINADOS PAÍSES 1948, 1953, 1963, 1973, 1983, 1993, 2003 E 2006

\begin{tabular}{|c|c|c|c|c|c|c|c|c|c|c|c|c|c|c|c|c|}
\hline \multirow{4}{*}{ Mundo } & \multicolumn{8}{|c|}{ Exportações } & \multicolumn{8}{|c|}{ Importações } \\
\hline & \multicolumn{8}{|c|}{ Valor } & \multicolumn{8}{|c|}{ Valor } \\
\hline & 59 & 84 & 157 & 579 & 1838 & 3675 & 7371 & 11783 & 62 & 85 & 164 & 595 & 1882 & 3770 & 7650 & 12113 \\
\hline & \multicolumn{8}{|c|}{ Participação } & \multicolumn{8}{|c|}{ Participação } \\
\hline Mundo & 100.0 & 100.0 & 100.0 & 100.0 & 100.0 & 100.0 & 100.0 & 100.0 & 100.0 & 100.0 & 100.0 & 100.0 & 100.0 & 100.0 & 100.0 & 100.0 \\
\hline América do Norte & 28.1 & 24.8 & 19.9 & 17.3 & 16.8 & 18.0 & 15.8 & 14.2 & 18.5 & 20.5 & 16.1 & 17.2 & 18.5 & 21.5 & 22.6 & 21.0 \\
\hline Estados Unidos & 21.7 & 18.8 & 14.9 & 12.3 & 11.2 & 12.6 & 9.8 & 8.8 & 13.0 & 13.9 & 11.4 & 12.3 & 14.3 & 16.0 & 17.0 & 15.8 \\
\hline Canadá & 5.5 & 5.2 & 4.3 & 4.6 & 4.2 & 4.0 & 3.7 & 3.3 & 4.4 & 5.5 & 3.9 & 4.2 & 3.4 & 3.7 & 3.2 & 3.0 \\
\hline México & 0.9 & 0.7 & 0.6 & 0.4 & 1.4 & 1.4 & 2.2 & 2.1 & 1.0 & 0.9 & 0.8 & 0.6 & 0.7 & 1.8 & 2.3 & 2.2 \\
\hline América do Sul e Central & 11.3 & 9.7 & 6.4 & 4.3 & 4.4 & 3.0 & 3.0 & 3.6 & 10.4 & 8.3 & 6.0 & 4.4 & 3.8 & 3.3 & 2.5 & 3.0 \\
\hline Brasil & 2.0 & 1.8 & 0.9 & 1.1 & 1.2 & 1.0 & 1.0 & 1.2 & 1.8 & 1.6 & 0.9 & 1.2 & 0.9 & 0.7 & 0.7 & 0.8 \\
\hline Argentina & 2.8 & 1.3 & 0.9 & 0.6 & 0.4 & 0.4 & 0.4 & 0.4 & 2.5 & 0.9 & 0.6 & 0.4 & 0.2 & 0.4 & 0.2 & 0.3 \\
\hline Europa & 35.1 & 39.4 & 47.8 & 50.9 & 43.5 & 45.4 & 45.9 & 42.1 & 45.3 & 43.7 & 52.0 & 53.3 & 44.2 & 44.8 & 45.3 & 43.1 \\
\hline Alemanha & 1.4 & 5.3 & 9.3 & 11.6 & 9.2 & 10.3 & 10.2 & 9.4 & 2.2 & 4.5 & 8.0 & 9.2 & 8.1 & 9.1 & 7.9 & 7.5 \\
\hline França & 3.4 & 4.8 & 5.2 & 6.3 & 5.2 & 6.0 & 5.3 & 4.2 & 13.4 & 11.0 & 8.5 & 6.5 & 5.3 & 5.6 & 5.2 & 5.1 \\
\hline Reino Unido & 11.3 & 9.0 & 7.8 & 5.1 & 5.0 & 4.9 & 4.1 & 3.8 & 5.5 & 4.9 & 5.3 & 6.3 & 5.6 & 5.8 & 5.2 & 4.4 \\
\hline Itália & 1.8 & 1.8 & 3.2 & 3.8 & 4.0 & 4.6 & 4.1 & 3.5 & 2.5 & 2.8 & 4.6 & 4.7 & 4.2 & 3.9 & 3.9 & 3.6 \\
\hline \multicolumn{17}{|l|}{ Comunidade dos Estados } \\
\hline Independentes (CEI) & - & - & - & - & - & 1.5 & 2.6 & 3.6 & - & - & - & - & - & 1.2 & 1.7 & 2.3 \\
\hline África & 7.3 & 6.5 & 5.7 & 4.8 & 4.5 & 2.5 & 2.4 & 3.1 & 8.1 & 7.0 & 5.2 & 3.9 & 4.6 & 2.6 & 2.1 & 2.4 \\
\hline África do Sul & 2.0 & 1.6 & 1.5 & 1.0 & 1.0 & 0.7 & 0.5 & 0.5 & 2.5 & 1.5 & 1.1 & 0.9 & 0.8 & 0.5 & 0.5 & 0.6 \\
\hline Oriente Médio & 2.0 & 2.7 & 3.2 & 4.1 & 6.8 & 3.5 & 4.1 & 5.5 & 1.8 & 2.1 & 2.3 & 2.7 & 6.2 & 3.4 & 2.7 & 3.1 \\
\hline Ásia & 14.0 & 13.4 & 12.5 & 14.9 & 19.1 & 26.1 & 26.2 & 27.8 & 13.9 & 15.1 & 14.1 & 14.9 & 18.5 & 23.3 & 23.1 & 25.0 \\
\hline China & 0.9 & 1.2 & 1.3 & 1.0 & 1.2 & 2.5 & 5.9 & 8.2 & 0.6 & 1.6 & 0.9 & 0.9 & 1.1 & 2.8 & 5.4 & 6.5 \\
\hline Japão & 0.4 & 1.5 & 3.5 & 6.4 & 8.0 & 9.9 & 6.4 & 5.5 & 1.1 & 2.8 & 4.1 & 6.5 & 6.7 & 6.4 & 5.0 & 4.8 \\
\hline Índia & 2.2 & 1.3 & 1.0 & 0.5 & 0.5 & 0.6 & 0.8 & 1.0 & 2.3 & 1.4 & 1.5 & 0.5 & 0.7 & 0.6 & 0.9 & 1.4 \\
\hline \multicolumn{17}{|l|}{ Austrália e Nova Zelândia } \\
\hline & 3.7 & 3.2 & 2.4 & 2.1 & 1.4 & 1.5 & 1.2 & 1.2 & 2.9 & 2.3 & 2.2 & 1.6 & 1.4 & 1.5 & 1.4 & 1.4 \\
\hline Six East Asian traders & 3.4 & 3.0 & 2.4 & 3.4 & 5.8 & 9.7 & 9.6 & 9.6 & 3.5 & 3.7 & 3.1 & 3.7 & 6.1 & 9.9 & 8.2 & 8.6 \\
\hline
\end{tabular}

FONTE: OMC (2008).

NOTA: Six East Asian traders refere-se aos seguintes países: Hong Kong, Malásia, Coréia do Sul, Singapura, Taiwan e Tailândia.

A tabela 2, a seguir, apresenta a relação comercial dos Estados Unidos com outros países e regiões. Fica evidente o déficit comercial norte-americano principalmente com os países asiáticos, com destaque para a China, que em 2006 representou aproximadamente 16\% das importações norte-americanas e apenas 5,3\% das exportações.

TABELA 2 - COMÉRCIO DE BENS DOS ESTADOS UNIDOS, POR REGIÕES E PAÍSES - 2006

\begin{tabular}{|c|c|c|c|c|c|c|c|}
\hline \multicolumn{4}{|c|}{ Exportações } & \multicolumn{4}{|c|}{ Importações } \\
\hline \multirow{2}{*}{ Destino } & \multirow{2}{*}{\begin{tabular}{|l|} 
Valor \\
2006 \\
\end{tabular}} & \multicolumn{2}{|c|}{ Part. (\%) } & \multirow{2}{*}{ Origem } & \multirow{2}{*}{$\begin{array}{l}\text { Valor } \\
2006 \\
\end{array}$} & \multicolumn{2}{|c|}{ Part. (\%) } \\
\hline & & 2000 & 2006 & & & 2000 & 2006 \\
\hline Mundo & 1038.3 & 100.0 & 100.0 & Mundo & 1919.4 & 100.0 & 100.0 \\
\hline América do Norte & 365.4 & 37.0 & 35.2 & América do Norte & 716.4 & 37.8 & 37.3 \\
\hline Ásia & 280.2 & 27.6 & 27.0 & Ásia & 508.4 & 29.4 & 26.5 \\
\hline Europa & 238.9 & 23.6 & 23.0 & Europa & 370.2 & 20.3 & 19.3 \\
\hline América do Sul e Central & 88.4 & 7.5 & 8.5 & América do Sul e Central & 140.6 & 6.2 & 7.3 \\
\hline Oriente Médio & 39.2 & 2.4 & 3.8 & Oriente Médio & 83.8 & 2.3 & 4.4 \\
\hline África & 19.0 & 1.4 & 1.8 & África & 74.7 & 3.2 & 3.9 \\
\hline CEI & 7.1 & 0.4 & 0.7 & CEI & 25.3 & 0.8 & 1.3 \\
\hline Canadá & 230.2 & 22.6 & 22.2 & União Européia & 339.8 & 18.6 & 17.7 \\
\hline União Européia & 214.5 & 21.5 & 20.7 & Canadá & 307.7 & 18.5 & 16.0 \\
\hline México & 134.3 & 14.3 & 12.9 & China & 305.8 & 8.5 & 15.9 \\
\hline Japão & 59.7 & 8.4 & 5.8 & México & 200.6 & 10.9 & 10.4 \\
\hline China & 55.2 & 2.1 & 5.3 & Japão & 152.3 & 12.0 & 7.9 \\
\hline
\end{tabular}

FONTE: OMC (2008). 
Por outro lado, a tabela 3 demonstra alguns efeitos do crescimento das economias asiáticas, com destaque para a China na demanda por bens no mercado internacional. Ao analisarmos a variação percentual de alguns setores nas exportações mundiais, observa-se o crescimento médio acima de 30\% de produtos advindos da indústria extrativa entre 2004 e 2006, bem com uma elevada taxa de crescimento na demanda por ferro e aço. Tal fenômeno resultou no aumento significativo do preço das commodities.

TABELA 3 - EXPORTAÇÕES MUNDIAIS POR PRODUTO - 2006

\begin{tabular}{|c|c|c|c|c|c|c|}
\hline \multirow{2}{*}{ Período } & \multirow{2}{*}{$\begin{array}{l}\text { Produtos } \\
\text { agrícolas }\end{array}$} & \multicolumn{2}{|c|}{$\begin{array}{c}\text { Combustíveis e produtos das } \\
\text { indústrias extrativas }\end{array}$} & \multicolumn{3}{|c|}{ Manufaturas } \\
\hline & & Combustíveis & Ferro e Aço & $\begin{array}{l}\text { Produtos } \\
\text { químicos }\end{array}$ & $\begin{array}{c}\text { Materiais de } \\
\text { escritório e de } \\
\text { telecomunicações }\end{array}$ & $\begin{array}{l}\text { Produtos da } \\
\text { indústria } \\
\text { automotiva }\end{array}$ \\
\hline $1980-85$ & -2 & -5 & -2 & 1 & 9 & 5 \\
\hline $1995-00$ & -1 & 12 & -2 & 4 & 10 & 5 \\
\hline $2000-06$ & 9 & 18 & 17 & 14 & 7 & 10 \\
\hline 2004 & 15 & 33 & 48 & 22 & 20 & 18 \\
\hline 2005 & 8 & 43 & 17 & 12 & 11 & 7 \\
\hline 2006 & 11 & 23 & 18 & 13 & 13 & 10 \\
\hline
\end{tabular}

FONTE: OMC(2008).

Ao analisarmos os dados apresentados até aqui, observa-se que o crescimento das economias asiáticas, lideradas pela China, tem gerado mudanças relevantes no mercado internacional. Porém, não há indícios de que a continuidade do crescimento chinês é suficiente para conter o alargamento da recessão norte-americana para o resto do mundo. Além disso, o mercado norte-americano tem sido um importante demandante da economia chinesa. Por outro lado, é importante ressaltar que a China também tem no mercado interno um motor importante para o crescimento. Basta observar através do gráfico 2, apresentado anteriormente, que mesmo diante das recessões norte-americanas ocorridas no início de 90 e de 2000, com repercussões importantes para o PIB mundial, a China manteve um crescimento médio de 10,1\% a.a, entre 1991 e 2006, sendo que a menor taxa observada no período foi de $7,6 \%$.

Portanto, estamos diante de um período de transição da divisão internacional do trabalho, com importantes repercussões geopolíticas, que se refletem nos preços relativos e conseqüentemente no comércio internacional. Basta considerar o fato de que a representatividade da economia chinesa no PIB mundial hoje é aproximadamente $50 \%$ maior do que a da América Latina em 1975, período próximo ao auge do crescimento da região. Se considerarmos a China e a Índia, esses países respondem por 37,3\% da população mundial (WDI, 2008) e em 2005 representavam aproximadamente 20,5\% do PIB mundial. 


\section{A INSERÇÃO DA ECONOMIA BRASILEIRA NO COMÉRCIO INTERNACIONAL E OS REFLEXOS DE UMA POSSÍVEL RECESSÃO}

A economia brasileira, apesar de manter uma baixa taxa média de crescimento econômico desde o início dos anos 80, tem apresentado uma mudança desta trajetória no período recente para o qual a taxa média de crescimento foi de aproximadamente $4,5 \%$, entre 2004 e 2007. Ao analisar sua inserção no comércio internacional, observa-se que apesar da pequena participação brasileira o país foi bastante beneficiado com o cenário internacional neste período e principalmente com o aumento da demanda internacional por commodities discutido anteriormente, o qual promoveu um aumento importante no preço internacional destes bens.

O gráfico 4 demonstra a trajetória dos preços das commodities a da taxa de câmbio efetiva real da moeda brasileira. Observa-se que a partir do início de 2003, quando o Real inicia um processo de valorização que ainda prossegue em fevereiro de 2008, o preço das commodities seguiu uma trajetória inversa, mas também intensa.

\section{GRÁFICO 4 - TAXA DE CÂMBIO EFETIVA REAL E PREÇO DAS COMMODITIES}

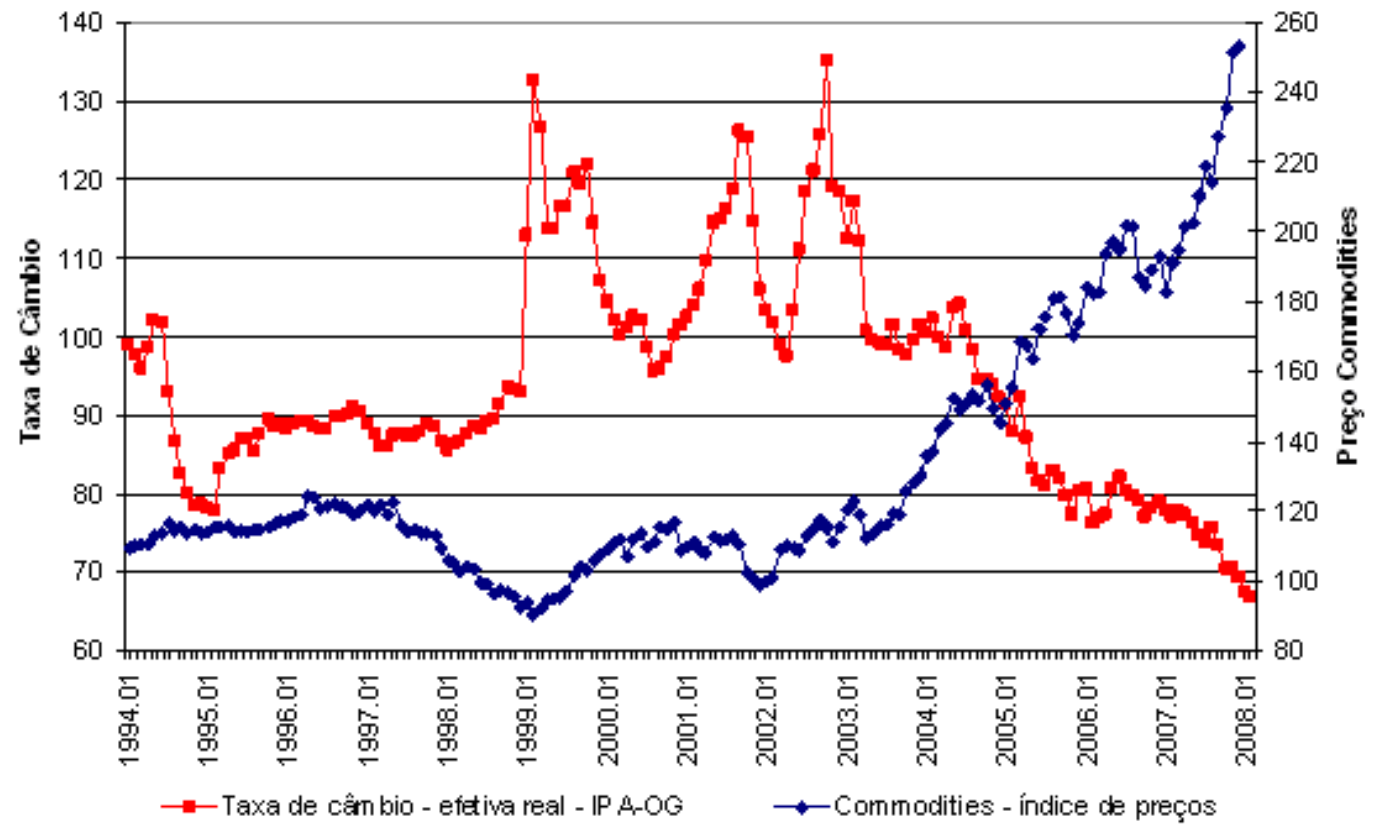

FONTE: IPEA.

A repercussão desta mudança nos preços relativos é observada claramente no resultado do comércio internacional brasileiro. Apesar da desvalorização cambial ocorrida em 1999, em momento algum, desde 1995 foram obtidos os resultados positivos na Balança Comercial brasileira observados a partir de 2003, mesmo diante da valorização do Real. 
GRÁFICO 5 - BALANÇA COMERCIAL, EXPORTAÇÕES E IMPORTAÇÕES DE BENS E SERVIÇOS E SALDO EM TRANSAÇÕES CORRENTES - BRASIL - 1995-2008

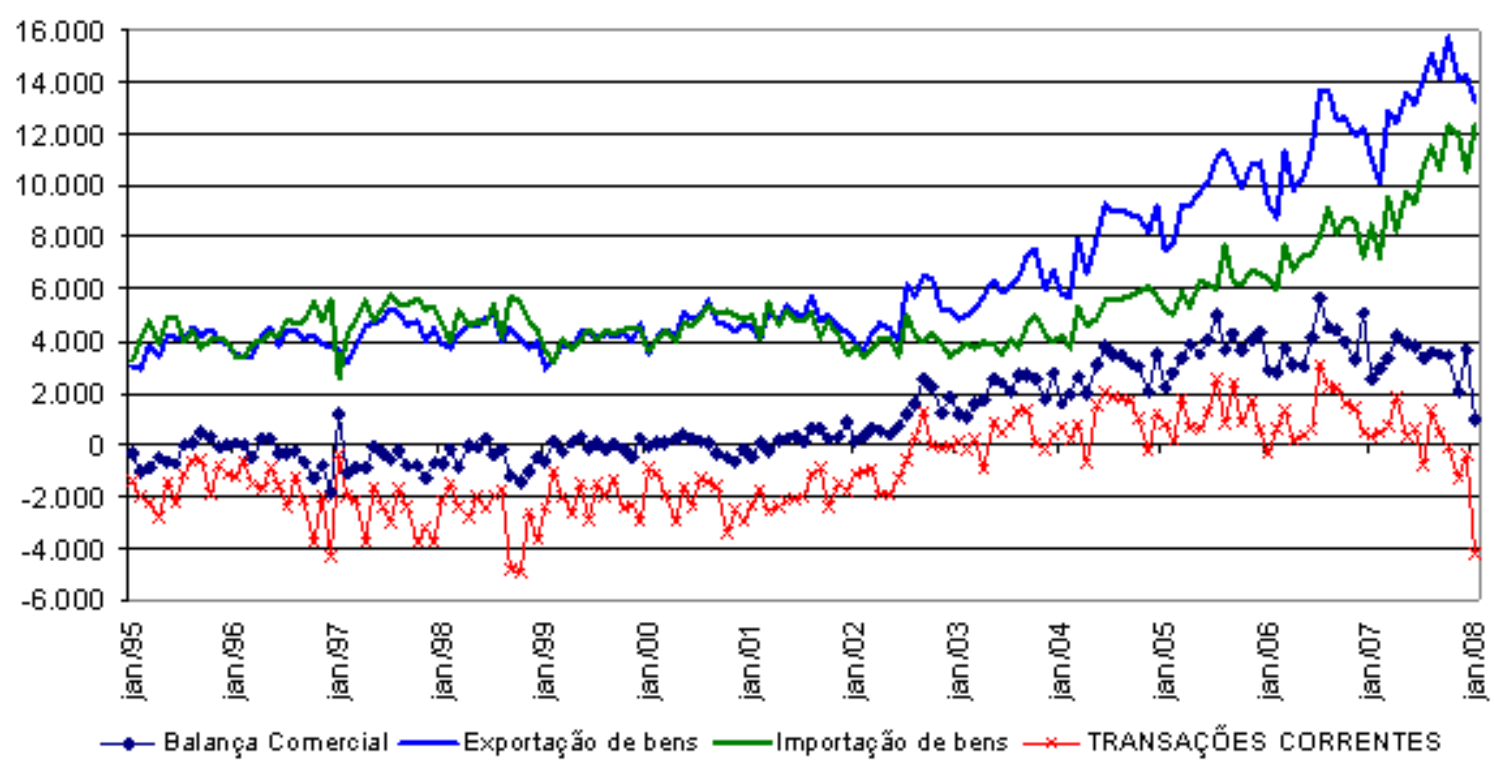

FONTE: Banco Central do Brasil (2008).

Os recordes alcançados recorrentemente pelas exportações brasileiras, mesmo com a valorização na taxa de câmbio, também propiciaram resultados positivos em Transações Correntes. O gráfico 6 abaixo, apresenta o resultado acumulado do saldo da Balança Comercial e em Transações Correntes, desde janeiro de 1995, ou seja, após a estabilidade monetária pós-Real. Desta forma, em janeiro de 2005, as variáveis apresentam valor igual a zero no gráfico em dois eixos, que passam a ter os saldos acumulados a partir de então.

Observa-se que as Transações Correntes brasileira acumularam déficits da ordem de US\$ 185 bilhões até meados de 2002. Numa escala muito menor, mas também apresentando um déficit estava o resultado acumulado da Balança Comercial. Ao longo de 2002 muda a trajetória do resultado acumulado pela Balança Comercial no período e o mesmo ocorre com as Transações Correntes, que passa a apresentar resultados superavitários e muda a inflexão da curva no gráfico.

Porém, ao final de 2007 e principalmente em 2008, observamos uma tendência à mudança desta trajetória que apesar de muito recente, apresenta-se de uma forma não observada desde 2002. O déficit em Transações Correntes em janeiro de 2008 é maior do que todos os déficits observados para o mês de janeiro, desde 1995, superando inclusive o de anos bastante turbulentos como o período 1998-99, marcado pela queda do regime de âncora cambial no país. 
GRÁFICO 6 - TRANSAÇÕES CORRENTES E BALANÇA COMERCIAL

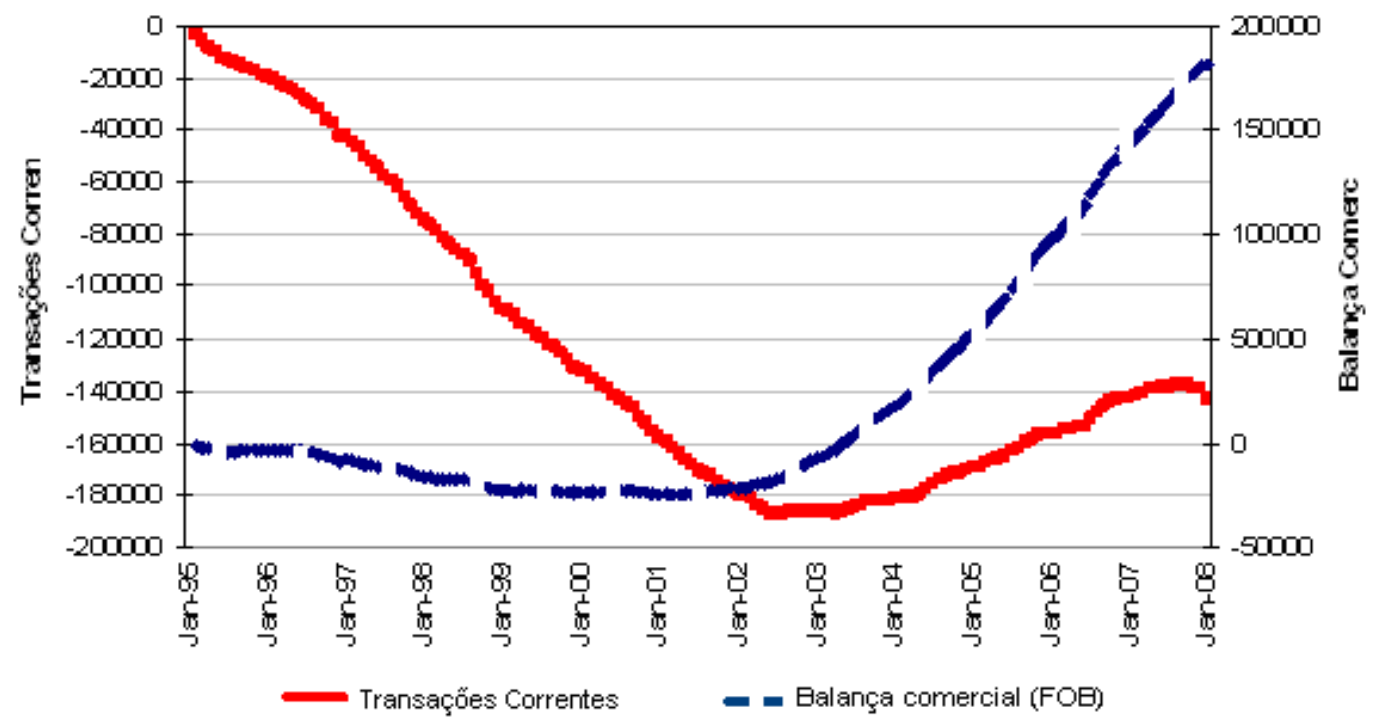

FONTE: Banco Central do Brasil (2008).

Outra questão importante a ser considerada é a mudança observada na pauta de exportação brasileira. Como seria de se esperar, com as informações apresentadas até então, está havendo um aumento da participação de bens básicos, que aumentaram sua participação em aproximadamente 10 pontos percentuais entre 1995 e 2007, conforme demonstra o gráfico 7. Apesar dos resultados positivos proporcionados pelo desempenho das exportações de bens básicos, esse tipo de especialização deve ser acompanhada com atenção, pelo fato de que ela pode acentuar o processo da valorização cambial, gerando perda de competitividade em setores de maior valor agregado.

GRÁFICO 7 - EXPORTAÇÃO BRASILEIRA POR FATOR AGREGADO - PARTICIPAÇÃO

Participaçẫo $(\%)$

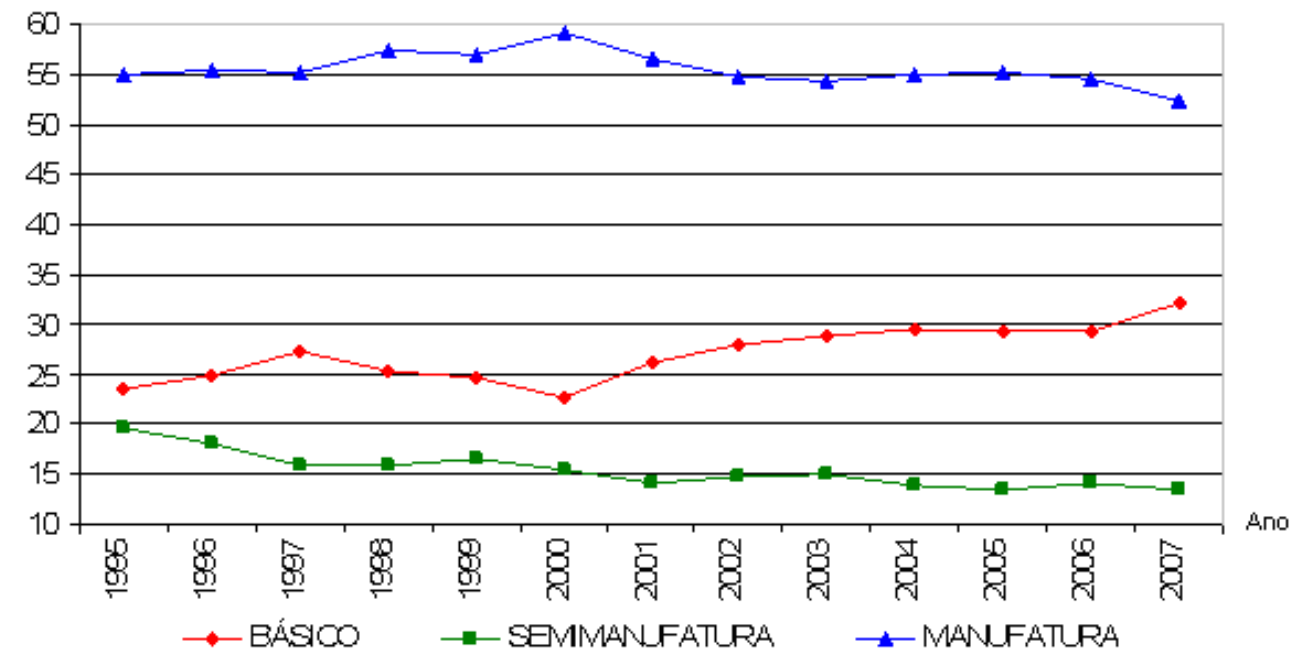

FONTE: MDIC (2008). 
Por fim, é importante ressaltar que os resultados positivos obtidos pela economia brasileira nos anos recentes, não são explicados apenas pela bonança externa. Ao se observar o gráfico 8 que apresenta a taxa de crescimento do PIB junto à variação dos componentes da demanda agregada, observa-se que as exportações tiveram uma participação muito importante para suavizar o fraco desempenho do PIB em 2003 e continuou com um papel importante em 2004. Porém, a partir deste ano, também o consumo das famílias passou a manter um crescimento contínuo e expressivo durante quatro anos seguidos, como não observado em nenhum outro período da série, com início em 1994.

Neste caso, é importante ressaltar o papel da expansão do crédito na economia brasileira. Além da queda da taxa de juros, observada a partir de 2005, também houve um alargamento dos prazos para concessão de crédito às famílias. As operações de crédito do sistema financeiro representavam aproximadamente 24\% do PIB no início de 2003 e terminaram 2007 com uma participação próxima de 35\%, de acordo com dados do Banco Central do Brasil, disponibilizados pelo IPEA.

GRÁFICO 8 - COMPOSIÇÃO DA TAXA DE CRESCIMENTO DO PIB - BRASIL - 1994 - 2007

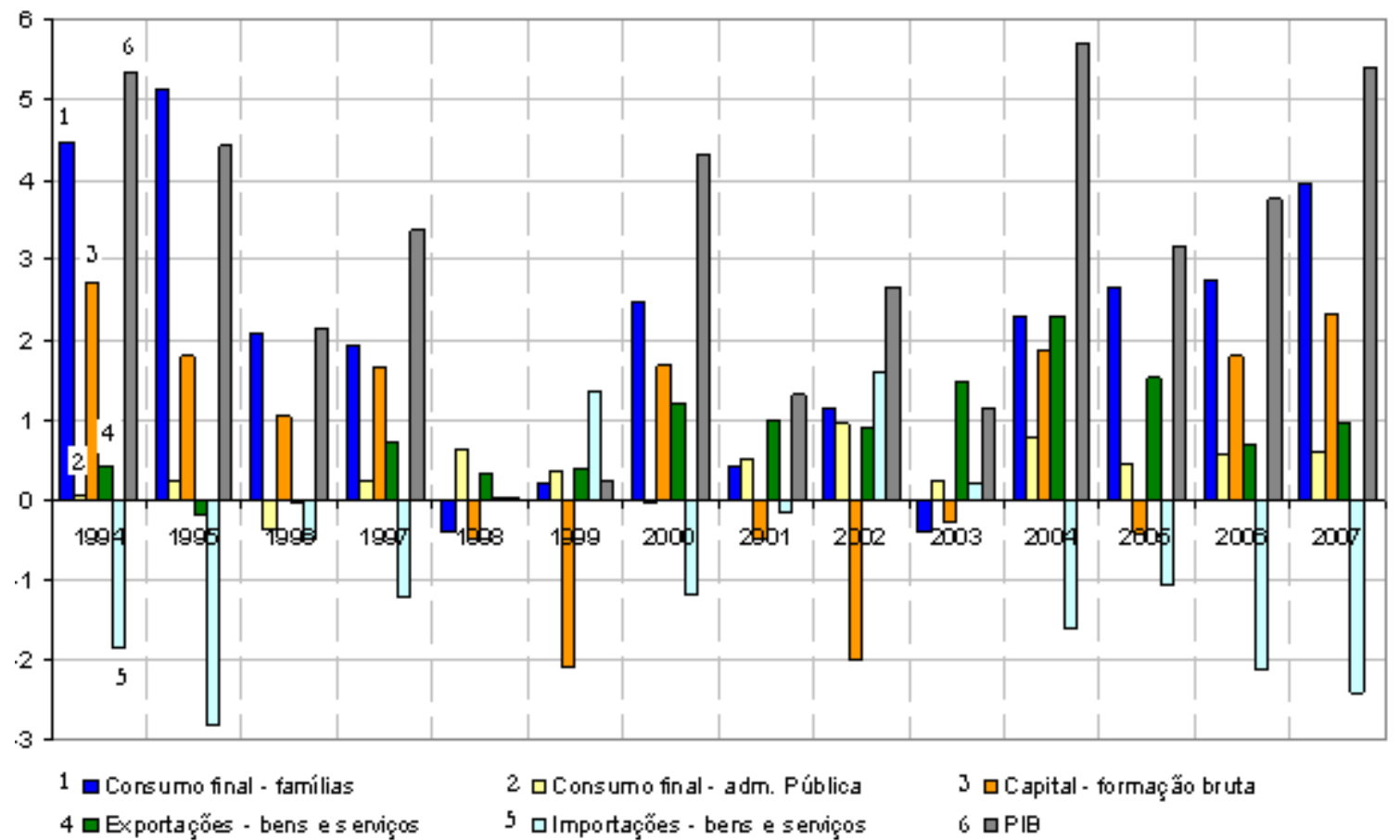

FONTE: IBGE (2008).

Desta forma, além de ser diretamente favorecido pelo cenário internacional, em virtude do aumento significativo do preço das commodities que são representativas em pauta de 
exportação, o Brasil também tem conseguido manter um bom desempenho do mercado interno.

A questão que se coloca, no entanto, é sobre a possibilidade de manter - no médio e longo prazo - um ritmo de crescimento adequado com base no mercado interno. As evidências internacionais têm sido claras em demonstrar que a manutenção do processo de crescimento, numa economia globalizada, depende fortemente da inserção externa do país, sobretudo para países emergentes, como o Brasil. A retração do comércio internacional que se anuncia para os próximos anos constitui-se, neste sentido, num limitador das possibilidades de expansão da economia brasileira.

\section{CONSIDERAÇÕES FINAIS}

A transição apontada pelo texto com respeito à economia mundial torna mais complexa as projeções para os efeitos de uma possível recessão norte-americana nos demais países, em especial o Brasil, uma vez que o cenário atual é muito distinto do observado nas últimas recessões. Por isso mesmo, não há fortes indícios de que as economias asiáticas e os demais países emergentes consigam de fato absorver os efeitos para as demais economias de uma recessão norte-americana. Porém, há indícios de que eles serão minimizados, em virtude do aumento da representatividade destas economias e da força de sua demanda interna.

Os efeitos da crise externa sobre a economia são diversos. Os principais, a nosso ver, poderiam ser assim sistematizados:

- A queda nos preços das commodities e a retração da demanda mundial devem alterar de modo substancial a situação externa brasileira. As previsões de superávit da Balança Comercial para este ano, de acordo com o Banco Central do Brasil, foram revistas de US $\$ 30$ bilhões para US $\$ 20$ bilhões, o que, em grande medida, reflete a expectativa de queda nestes preços;

- O retorno do déficit em transações correntes é aparentemente inevitável neste contexto de redução do superávit comercial. As remessas de lucros e dividendos também devem contribuir de forma significativa para este resultado;

- O aumento do grau de incerteza deve contribuir para uma redução dos fluxos de capitais para países emergentes. A drástica redução dos fluxos de IDE para o Brasil neste início de ano é um exemplo deste novo cenário. 
- Os elevados níveis de reserva internacional do país irão amenizar substancialmente estes efeitos da crise sobre o setor externo.

- Caso este contexto venha a se confirmar, as pressões para valorização do Real devem ser relativamente contidas, pelo menos no curto prazo, o que diminui a pressão competitiva sobre a indústria brasileira. Este cenário, no entanto, pode ser alterado se ocorrer um endurecimento da política monetária, o que, até o momento afigura-se como relativamente improvável;

- Por fim, a crise externa não deve modificar substancialmente o ritmo de expansão brasileira no curto prazo. A maioria dos analistas prevê a manutenção de um bom ritmo de crescimento para este ano. No entanto, as possibilidades de manutenção do crescimento com base no mercado interno no longo prazo, num contexto de redução do crescimento mundial, são limitadas.

\section{REFERÊNCIAS}

SÉRIE HISTÓRICA DO BALANÇO DE PAGAMENTOS DO BRASIL. Brasília: Banco Central do Brasil. Disponível em <http://www.bc.gov.br>. Acesso em: 10/03/2008.

WORLD DEVELOPMENT INDICATORS. Washington: Banco Mundial, 2007. Disponível em: http://www.worldbank.org/. Acesso em: Acesso em: 5/03/2008.

CONTAS NACIONAIS DO BRASIL. Brasília: IBGE. Disponível em <http://www.ibge.gov.br>. Acesso em: 10/03/2008.

SÉRIE HISTÓRICA DA TAXA REAL DE CÂMBIO E PREÇO DE COMMODITIES INTERNACIONAIS. Brasília: IPEA.. Disponível em <http://www.ipeadata.gov.br>. Acesso em: 5/03/2008.

ESTATÍSTICAS DO SETOR EXTERNO BRASILEIRO. Brasília: Ministério do Desenvolvimento, Indústria e Comércio - MDIC. Disponível em <http://www.mdic.gov.br>. Acesso em: 05/03/2008.

ESTATÍSTICAS DO COMÉRCIO INTERNACIONAL. Genebra: OMC - Organização Mundial do Comércio. Disponível em <http://www.wto.org>. Acesso em 05/03/2008.

40 